\title{
WEAR PERFORMANCE OF NANO-COMPOSITE ARTIFICIAL DENTURE TEETH
}

\author{
Muhammad Abbas* and Hassan Sakr **
}

\begin{abstract}
Statement of Problem: Civilizing the wear resistance of artificial denture teeth is of importance to prosthodontic patients, as wear may affect the denture esthetics and functions. To counteract this problem, artificial teeth with increased wear resistance had been introduced in the market.

Aim: The aim of the current study was to compare the amount of wear between nanocomposite and acrylic (PMMA) artificial teeth.

Materials and methods: Ten teeth were fabricated (reproduced) from nanocomposite (Z350) by duplicating one tooth from the ready-made conventional acrylic artificial teeth. Fifteen artificial teeth were chosen from ready-made acrylic resin teeth. Mandibular $1^{\text {st }}$ molars were only chosen for testing. The 2-body wear testing was performed using multi-modal ROBOTA chewing simulator. Test samples were mounted against 600 grit sandpaper and tested under a load of 700 gram for 10,000 cycles of rotation. Height and weight were measured before and after wear test for each specimen to determine the loss in both. Qualitative analysis of the wear areas was completed using USB Digital microscope with a built-in camera connected with an IBM compatible personal computer using a fixed magnification of 25X. Results: It was found that Nano-composite group recorded higher height loss mean value than conventional group height loss mean value. The difference between both groups was statistically non-significant $(\mathrm{p}>0.05)$ as indicated by unpaired t-test. Also Nanocomposite group recorded higher weight loss mean value than conventional group weight loss mean value. The difference between both groups was statistically non-significant $(p>0.05)$ as indicated by unpaired t-test.
\end{abstract}

Conclusions: Nano-composite teeth exhibited non-significant higher wear than conventional artificial acrylic teeth.

KEYWORDS: Wear- Nanocomposite teeth- Acrylic teeth

\footnotetext{
* Assistant Professor, Dental Biomaterials Department, Faculty of Dental medicine, Al-Azhar University, Egypt ** Assistant Professor, Removable Prosthodontics Department, Faculty of Dental medicine, Al-Azhar University, Egypt
} 


\section{INTRODUCTION}

The prosthetic teeth restore the form, function and esthetics of a completely edentulous patient thereby enhance the quality of mastication, speech and provide psychological comfort for them, and hence fabrication of a removable prosthesis requires selection of denture teeth with superior properties ${ }^{(1)}$. "Wear" is defined as the loss of a substance due to continual use. In dentistry, wear occurs when two articulating surfaces undergo slipping and sliding movements against one another when a load is applied. The Institute of Mechanical Engineers of UK defined wear as "the progressive loss of substance from a body brought about by mechanical action"(2). High wear resistance help maintain the properly established occlusal vertical dimension, chewing efficiency, proper occlusal relationship to decrease the horizontal stresses and result in maintenance of esthetics and function ${ }^{(3)}$. Denture teeth wear is a complex process which occurs due to multiple factors namely: chewing habits, diet, parafunctional habits, anatomy of the supporting residual ridges and material of the prosthetic teeth ${ }^{(1,2)}$. Among the above factors enlisted, the operator can control the wear by selecting the prosthetic teeth which has less wear. Prosthetic teeth with less wear increases the longevity of the denture as stated by Reis et al. ${ }^{(4)}$

Early literature on artificial teeth stated that stone, wood, ivory and even human teeth were used for teeth replacements ${ }^{(1)}$. Modern Prosthodontics commonly utilizes porcelain, acrylic, and composite teeth for denture fabrication ${ }^{(4-6)}$. Porcelain teeth were the first denture teeth to be used in dentistry. Although they exhibit superior resistance to wear, they possess a number of major disadvantages such as lack of bonding to the denture base, brittleness, and high hardness which leads to the abrasion of natural enamel and other restorative materials ${ }^{(7)}$. Acrylic teeth were introduced in the 1930s with polymethylmethacrylate (PMMA) the most commonly used. By 1950, almost 98\% of all acrylic denture teeth used were PMMA ${ }^{(8)}$. Acrylic teeth solved some of porcelain denture teeth's problems, including brittleness, ease of contouring custom anatomical form, high resilience and chemical bond to denture base; however, excessive wear was still a major concern, since acrylic denture teeth can go through rapid change in occlusal morphology in a short period of time ${ }^{(9,10)}$.

One of the materials that have emerged over the years for manufacturing the prosthetic teeth is composite resin. Mixing Bis-GMA with diluting monomers and adding glass or silica powder initiated the era of composites. Initially introduced composite teeth are microfilled composites which did not meet the esthetic requirements of prosthetic teeth because of poor polishability, but nanocomposite teeth which was refined by controlling the size of the filler particles was highly polishable thus improving the esthetics ${ }^{(11)}$. With the advancement in the field of nanotechnology, researchers developed the sialinized silicon inorganic nanofillers of less than $50 \mathrm{~nm}$, for the composite matrix of Urethane dimethyl methaacrylate (UDMA) and PMMA which thereby led to the introduction of nanocomposite teeth without much compromise in the mechanical properties and superior esthetics ${ }^{(12)}$.

Clinical trials are the best way to evaluate the wear of denture teeth in denture wearers; however, several intraoral factors, such as salivary $\mathrm{pH}$, diet, oral hygiene, and neuromuscular force, can influence the wear results. Therefore, wear resistance is better studied when evaluated using in vitro methods ${ }^{(13)}$.

Various studies had been done comparing the property of wear resistance of artificial teeth. Ghazal and Kern evaluated the wear resistance of four artificial denture teeth namely feldspathic ceramic, nano-filled composite resin, experimental acrylic resin with UDMA/PMMA, and IPN acrylic resin (AR) teeth. In this study, composite teeth exhibited less wear than that of acrylic teeth. Composite teeth with nanofillers were stated to have more amount of wear compared to composite teeth with traditional microfillers in the same experiment ${ }^{(14)}$. Ogle 
and Davis showed that IPN teeth (Bioform IPN; Dentsply, York, PA) wear less than conventional acrylic teeth (Biotone; Dentsply) by $28 \%$ after 3 years of clinical use (3). Coffey et al studied the in vitro wear resistance of conventional acrylic resin (Bioform; Dentsply) with crosslinked IPN (Bioform IPN) denture teeth in a wet environment. They found that IPN teeth exhibit less wear than noncrosslinked acrylic resin teeth when opposing each other ${ }^{(15)}$.

Nano-composite denture teeth have been developed to overcome problems with staining, wear resistance, and polishability (16). Several authors demonstrated greater wear resistance of nano-composites in contrast to IPN, DCL, and uncrosslinked acrylic denture teeth ${ }^{(17,18)}$. In 2009 , new nanohybrid composite (NHC) denture teeth (SR Phonares; Ivoclar Vivadent) were introduced to the market. The new nano-hybrid composite consists of a combination of UDMA matrix with three different fillers and PMMA clusters embedded in the structure. The first type of filler is inorganic densified silanized $\mathrm{SiO} 2$, which is used to strengthen the matrix and increase the material's hardness and wear resistance. The second type of filler is silanized $\mathrm{SiO} 2$ nanoparticle, which is used to strengthen the composite structure and to help decrease the wear of the opposing tooth structure. The third type of filler is inorganically filled DMA polymer,which is added to reduce polymerization shrinkage stress. A thorough Medline search revealed no reported scientific data in the literature. Only two poster presentations have been made relevant to NHC denture teeth. One poster was presented by Hahnel et al. at the International Association for Dental Research (IADR) annual meeting in Barcelona, Spain, 2010, in which they performed an in vitro comparison of NHC denture teeth (SR Phonares) to unfilled PMMA (Premium 6; Heraeus Kulzer, Hanau, Germany), filled PMMA (Vitapan; Vita, Bad Sackingen, Germany), and DCL acrylic (SR Vivodent DCL; Ivoclar Vivadent) denture teeth. They concluded that NHC denture teeth showed low values for height and volume loss, indicating promising wear behavior in vivo ${ }^{(12)}$.

A second poster was also presented at the 2010 IADR by Latta and Shaner) in which they performed an in vitro comparison of NHC denture teeth (SR Phonares) with nonfilled PMMA (IPN classic; Dentsply), filled PMMA(SR Vivodent DCL) denture teeth and micro-filled composite (SR Orthosit; Ivoclar Vivadent) denture teeth. They found that the NHC and micro-filled composite denture teeth were similar in wear resistance and superior to the nonfilled PMMA and the filled PMMA acrylic denture teeth ${ }^{(19)}$. In both posters, the detailed methodology and results were not available. There is little or no literatures about nano-composite resin artificial teeth and their wear properties.

The aim of this study was to compare the wear resistance of nanofilled composite teeth fabricated from Filtek Z350XT composite resin to acrylic denture teeth fabricated from heat cure PMMA.

\section{MATERIALS AND METHODS}

In this study, two materials (Nano-filled composite; Filtek Z350 XT Universal Restorative, 3M ESPE, St. Paul, MN, USA and Acrylic denture teeth; Acrostone. Headquarters, London, England) were used for manufacturing of the artificial teeth that tested to simulate wear under functional intraoral occlusion using two body wear testing method. Sample size was determined based on the previous studies using statistical formulae and determined as 15 samples per group and the power of the study was set as 80 with $95 \%$ confidence interval ${ }^{(4)}$. Table 1 shows the types, manufacturer and composition of materials used for the manufacturing of the tested artificial teeth.

Die Making (Duplicating the metal rod that fits the receptacle in upper compartment into acrylic rod (cylinder)

The sample to be tested with the ROBOTA chewing simulator must have a prescribed 
dimension recommended by the manufacturer for that machine. ROBOTA machine has a receptacle into which the sample can be mounted and tightened by screw. A model of the metal analog which fits into the receptacle was obtained and duplicated with acrylic. Putty impression of a cylindrical metal analog with the dimensions of $14 \mathrm{~mm}$ height and $9 \mathrm{~mm}$ in diameter was made. Cold cure acrylic resin was packed in the mold space and acrylic cylinder was formed. Thickness of the $1^{\text {st }}$ molar teeth obtained from a ready-made acrylic artificial teeth shades was measured with digital micrometer that showed $4 \mathrm{~mm}$ height. Ker acrylic teeth were bonded to the acrylic cylinder with cyanoacrylate. The entire setup after bonding measured $18 \mathrm{~mm}$ in height using a fine digital micrometer (Mitutoyo
Digimatic Caliper 25SB, Mitutoyo Corporation, Japan) with a precision of 1/1000 (Fig. 1).

The entire setup which fits into the receptacle of the upper compartment of ROBOTA machine was obtained and duplicated with the materials tested as denture artificial teeth.

\section{Duplication with Nanocomposite resin (FiltekZ350XT) material (Fig. 1):}

- Putty impression of the model (acrylic cylinder with bonded Ker teeth) was taken.

- Light cure nanocomposite resin was packed in the mold space layer by layer and light cured for 60 seconds for each layer until filling the crown portion in the mold, then cold cure acrylic

TABLE (1) Denture teeth materials used in the study.

\begin{tabular}{|l|l|l|}
\hline Denture teeth material & Manufacturer & Composition \\
\hline \multirow{4}{*}{ Nano-composite resin } & $\begin{array}{l}\text { Filtek Z350 XT Universal } \\
\text { Restorative, 3M ESPE, } \\
\text { St. Paul, MN, USA }\end{array}$ & $\begin{array}{l}\text { - Organic matrix: Bis-GMA, BisEMA UDMA, TEGDMA } \\
\text {-Type of filler: } \\
\text { Silica nanocluster, cluster } \\
\text {-Filler \%: } 57 \\
\text {-Mean particle size of filler (um): Nanocluster: } 0.075 \\
\text { Cluster: } 0.64 \text { - 1.4 }\end{array}$ \\
& & Cross linked PMMA \\
\hline $\begin{array}{l}\text { Conventional heat cured } \\
\text { acrylic resin }\end{array}$ & $\begin{array}{l}\text { Acrostone. Headquarters, } \\
\text { London, England }\end{array}$ & \\
\hline
\end{tabular}

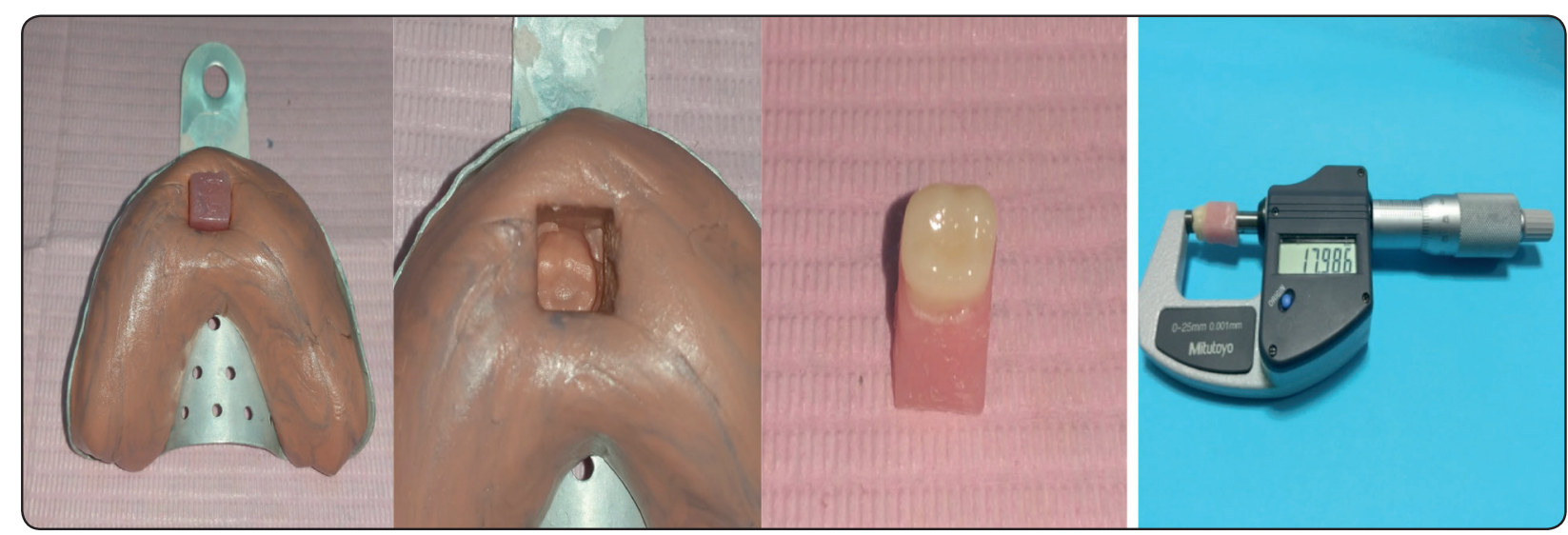

Fig. (1) Duplication of acrylic cylinder with bonded Ker $1^{\text {st }}$ molar artificial tooth \& Digital micrometer measuring the height of the cylinder with bonded tooth 
resin was packed in the remaining mold space and acrylic cylinder with composite artificial teeth were formed. Fifteen specimens were reproduced in the same manner.

\section{Duplication with ready-made acrylic resin ma- terials:}

- The same process was followed for fabricating the 15 samples of the remaining tested acrylic resin materials.

The nanocomposite teeth were assigned as group A, acrylic teeth as group B. All specimens were stored in $37^{\circ} \mathrm{C}$ water for 24 hours prior to testing.

\section{Wear test}

The 2-body wear testing was performed using a programmable logic controlled equipment using the newly developed four stations multimodal Dual-axis ROBOTA chewing simulator (Fig. 2) integrated with thermo-cyclic protocol operated on servo-motor (Model ACH-09075DC-T, AD-TECH Technology Co., LTD., Germany). The device allows simulation of the vertical and horizontal movements simultaneously in the thermodynamic condition. ROBOTA chewing simulator which has four chambers. Each chamber consists of an upper Jackob's chuck as tooth or antagonist holder and a lower plastic sample holder. Samples were mounted into the metal receptacle present in the chewing simulator; upper Jackob's chuck as tooth holder that can be tightened with a screw (Fig. 2a). All the samples were tested under standard conditions in which 600 grit sandpaper was used in the lower compartment of the device (Fig. 2b) as antagonist based on previous research studies ${ }^{(11,13)}$. The sample was positioned on the machine in such a way that the cusps of the molars were in point contact with the sandpaper. A weight of 700 gram, which is comparable to $7 \mathrm{~N}$ of chewing force was exerted.

Teeth were subjected to a revolution of 10,000 cycles which run approximately for $54 \mathrm{~min}$. After 10,000 cycles, the specimens were removed from the holder, cleaned with running water, and followed by cleaning in ultrasonic cleaner for 2 minutes to remove any abraded particles from the surface of the specimens prior to measuring. The weight and height was checked to calculate the loss of both. Table 2 demonstrated the wear test parameters of the ROBOTA chewing simulator device.

\section{Wear measurements}

Substance loss of the specimens after loading was measured by weight and height loss. Height loss was achieved with the digital micrometer. The difference between the readings before and after the wear simulation gave the amount of vertical substance loss.

Weight loss was done by weighing samples in the electronic analytical balance (Sartorius, Biopharmaceutical and Laboratories, Germany) with an accuracy of 0.0001 gram to show the difference in weight before and after wear test. As this electronic balance had a fully automated calibration technology and a micro weighing scale, values of all the mounted discs and antagonist samples were accurately measured. Each mounted sample was cleaned and dried with tissue paper before weighing. To ensure accuracy, the balance was kept on a free standing table at all times away from vibrations and weighed the specimens with the glass doors of the balance closed to avoid the effect of air drafts.

Miscroscopic evaluation: To achieve a better reflection on the surface of the teeth and qualitative analysis of the wear areas, wear of both the buccal and lingual cusps were photographed using USB Digital microscope with a built-in camera (Scope Capture Digital Microscope, Guangdong, China) connected with an IBM compatible personal computer using a fixed magnification of $25 \mathrm{X}$

Statistical analysis: Paired t-test was done to compare effect of wear simulation on each group. Unpaired t-tests were performed to detect 


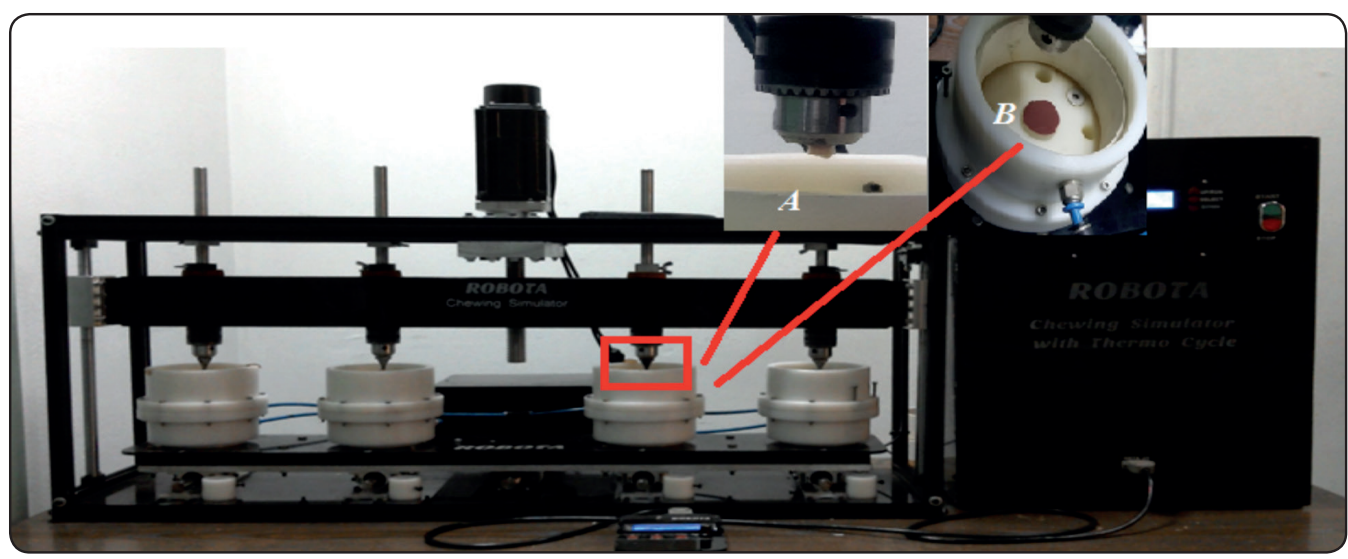

Fig. (2) ROBOTA chewing simulator with four chambers (a) Samples mounted and tightened into the metal receptacle in the upper compartment (b) 600 grit sandpaper as antagonist material in the lower compartment

significance between main groups. Statistical analysis was performed using Aasistat 7.6 statistics software for Windows (Campina Grande, Paraiba state, Brazil). $\mathrm{P}$ values $\leq 0.05$ are considered to be statistically significant in all tests.

TABLE (2) Wear test parameters of ROBOTA chewing simulator machine

\begin{tabular}{|c|c|}
\hline \multicolumn{2}{|c|}{ Wear test parameters } \\
\hline Vertical movement: $1 \mathrm{~mm}$ & $\begin{array}{l}\text { Horizontal movement: } \\
\qquad 5 \mathrm{~mm}\end{array}$ \\
\hline Rising speed: $90 \mathrm{~mm} / \mathrm{s}$ & Forward speed: $90 \mathrm{~mm} / \mathrm{s}$ \\
\hline Descending speed: $40 \mathrm{~mm} / \mathrm{s}$ & Backward speed: $40 \mathrm{~mm} / \mathrm{s}$ \\
\hline Cycle frequency $1.6 \mathrm{~Hz}$ & $\begin{array}{l}\text { Weight per sample: from } \\
700 \mathrm{gr}\end{array}$ \\
\hline \multicolumn{2}{|c|}{ Torque; 2.4 N.m } \\
\hline
\end{tabular}

\section{RESULTS}

\section{Height results:}

The mean values and standard deviations (SD) for wear test measured by height loss $(\mathrm{mm})$ recorded for both experimental groups before and after 10000 mastication simulation cycles are summarized in table (3).
It was found that nano-composite group recorded statistically significant higher height mean value $(16.263 \pm 1.23 \mathrm{~mm})$ before wear simulation than after mean value $(15.825 \pm 1.15 \mathrm{~mm})$ with mean height loss $(0.7738 \pm 0.66 \mathrm{~mm})$ as indicated by paired t-test $(\mathrm{t}=9.49, \mathrm{p}=0.0006<0.05)$

It was found that conventional group recorded statistically significant higher height mean value $(18.239 \pm 0.42 \mathrm{~mm})$ before wear simulation than after mean value $(17.937 \pm 0.45 \mathrm{~mm})$ with mean height loss $(0.30175 \pm 0.08 \mathrm{~mm})$ as indicated by paired t-test $(\mathrm{t}=6.1, \mathrm{p}=0.0036<0.05)$

It was found that nano-composite group recorded higher height loss mean value $(0.4379 \pm 0.087 \mathrm{~mm})$ than conventional group height loss mean value $(0.30175 \pm 0.08 \mathrm{~mm})$. The difference between both groups was statistically non-significant $(\mathrm{p}>0.05)$ as indicated by unpaired t-test.

\section{Weight results}

The mean values and standard deviations (SD) for wear test measured by weight loss (gram) recorded for both experimental groups before and after 10000 mastication simulation cycles summarized in table (4).

It was found that nano-composite group recorded statistically significant higher weight mean value $(1.442892 \pm 0.098$ gram) before wear simulation than after mean value $(1.4392 \pm 0.099$ gram $)$ with 
mean weight loss $(0.003692 \pm 0.001708$ gram $)$ as indicated by paired $\mathrm{t}$-test $(\mathrm{t}=4.01, \mathrm{p}=0.0145<0.05)$

It was found that conventional group recorded statistically significant higher weight mean value (1.8269 \pm 0.1097 gram) before wear simulation than after mean value $(1.825688 \pm 0.145 \mathrm{gram})$ with mean weight loss $(0.001708 \pm 0.0005 \mathrm{gram})$ as indicated by paired t-test $(\mathrm{t}=5.3, \mathrm{p}=0.006<0.05)$.

It was found that nano-composite group recorded higher weight loss mean value $(0.003692 \pm 0.001708$ gram) than conventional group weight loss mean value $(0.001708 \pm 0.0005$ gram $)$. The difference between both groups was statistically nonsignificant $(\mathrm{p}>0.05)$ as indicated by unpaired t-test.

\section{Microscopic evaluation}

Microscopic images of a nano-composite teeth and acrylic teeth examined at $25 \mathrm{X}$ magnification were represented in figures 3 , and 4 . From figure (b), it can be observed that there is a significant surface wear in regard to the surface before wearing (figure a). Also, Wear of both buccal and lingual cusps was occurred evenly.

TABLE (3) Height results (Mean values \pm SD) before and after wear simulation and height loss for both experimental groups

\begin{tabular}{|l|l|c|c|c|c|}
\hline \multirow{2}{*}{\multicolumn{2}{|c|}{ Variables }} & \multicolumn{3}{|c|}{ Height results (mm) } & t-test \\
\cline { 3 - 6 } & Before & After & Height loss & P value \\
\hline $\begin{array}{l}\text { Experimental } \\
\text { Groups }\end{array}$ & Nano-composite & $16.263 \pm 1.23$ & $15.825 \pm 1.15$ & $0.4379 \pm 0.07$ & 0.0789 \\
\cline { 2 - 5 } & Conventional & $18.239 \pm 0.42$ & $17.937 \pm 0.45$ & $0.30175 \pm 0.08$ & $\mathrm{~ns}$ \\
\hline
\end{tabular}

ns; non-significant ( $p>0.05)$

TABLE (4) Weight results (Mean values \pm SD) before and after wear simulation and weight loss for both experimental groups

\begin{tabular}{|c|l|c|c|c|c|}
\hline \multicolumn{2}{|c|}{ Variables } & \multicolumn{3}{c|}{ Weight results } & ANOVA \\
\cline { 3 - 7 } \multicolumn{2}{|c|}{} & Before & After & Weight loss & P value \\
\hline \multirow{2}{*}{$\begin{array}{c}\text { Experimental } \\
\text { groups }\end{array}$} & Nano-composite & $1.442892 \pm 0.098$ & $1.4392 \pm 0.099$ & $0.003692 \pm 0.001708$ & 0.0825 \\
\cline { 2 - 5 } & Conventional & $1.8269 \pm 0.1097$ & $1.825688 \pm 0.145$ & $0.001708 \pm 0.0005$ & $\mathrm{~ns}$ \\
\hline
\end{tabular}

ns; non-significant ( $p>0.05)$

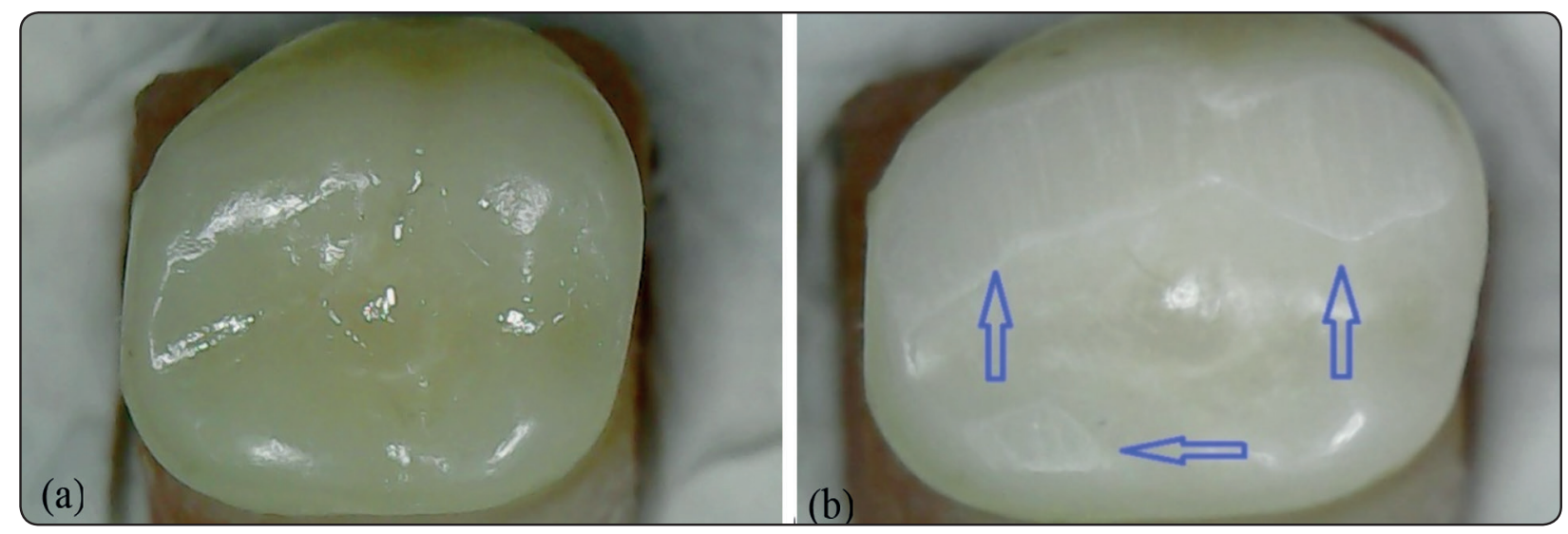

Fig. (3) Photomicrograph of nanocomposite teeth; before wear (a), after wear (b) 


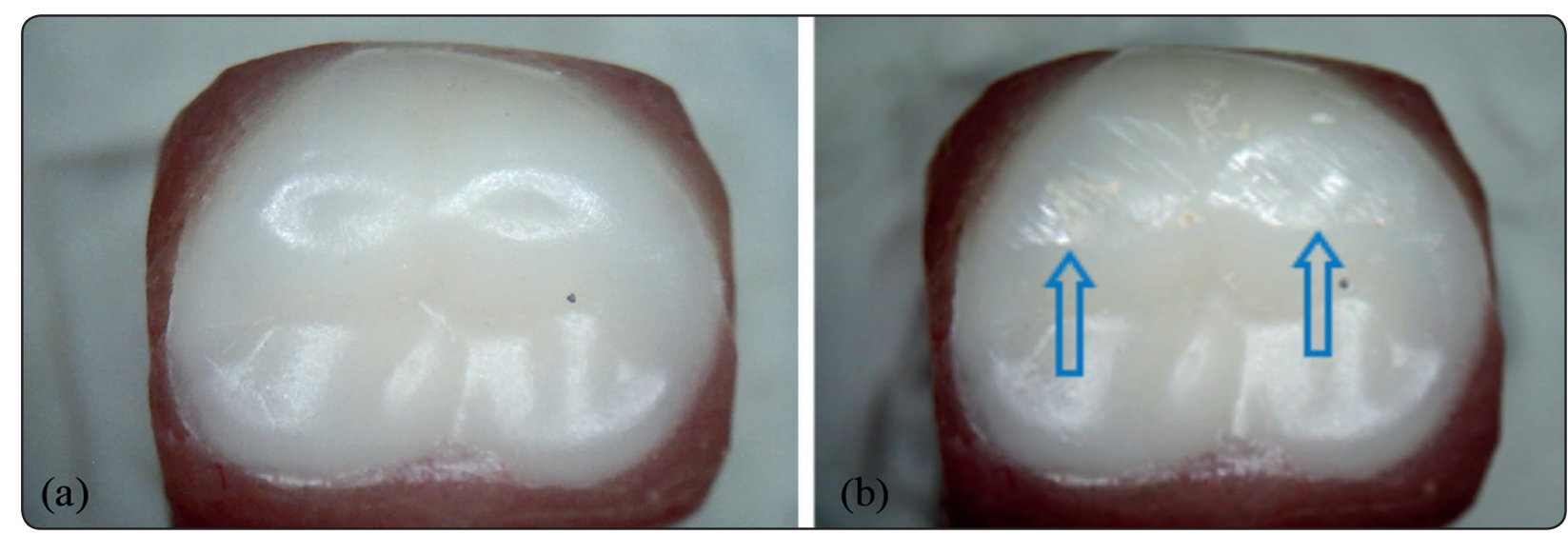

Fig. (4) Photomicrograph of acrylic teeth, before wear test (a), after wear (b)

\section{DISCUSSION}

The wear of enamel opposing enamel is $20-40$ $\mu \mathrm{m} / \mathrm{year}$ and an ideal artificial material should mimic that ${ }^{(20)}$. Excessive wear of prosthetic artificial teeth, restoration or the entire dentition may be associated with supra-eruption of opposing teeth, periodontal breakdown, traumatic occlusion, loss of vertical dimension and even temporomandibular joint dysfunction ${ }^{(21)}$. Acrylic resin teeth are the most widely used denture teeth. They have the distinct advantage of adjustability, lack of clicking sounds and good bonding to denture base material when compared to porcelain teeth, but acrylic resin has the disadvantage of poor wear resistance. Posterior teeth are used for chewing and encounter increased load when compared to anterior teeth. Hence posterior acrylic denture teeth tend to wear faster than the anterior acrylic denture teeth ${ }^{(4,13)}$; therefore $1^{\text {st }}$ molars were used in this study. Also, $1^{\text {st }}$ molar teeth were chosen to standardize the samples for comparison.

This in vitro study compared the amount of wear which occurred under same laboratory conditions between nanocomposite and acrylic teeth materials using a two-body wear testing machine. The wear of denture teeth can be studied in vitro by either two- or three-body testing methods. Three-body testing usually measures wear characteristics, but the results can be affected by many variables like the abrasiveness of the intermediate material and the $\mathrm{pH}$ of this material in addition to the material of the antagonist ${ }^{(20)}$. The two-body wear testing method, on the other hand shows the effect of direct contact between the specimen and the antagonist, as in the case of complete denture with bilaterally balanced occlusion. Although this contact between the maxillary and mandibular denture does not occur significantly during mastication of food, it normally occurs during swallowing and parafunctional habits that lead to wear of denture teeth. Therefore, the two-body wear test was selected in this study. As the oral cavity displays masticatory cycles ranging $5,000-30,000$ cycles in a month, to simulate this condition a wear cycle of 10,000 was selected. This was in accordance with study done by Hirano et $\mathrm{al}^{(22)}$.

Nanocomposite teeth have statistically nonsignificant higher wear than heat cured denture teeth. This result is in agreement with Munshi et al ${ }^{(7)}$, whom evaluated the wear resistance of nanocomposite denture teeth as compared to two acrylic denture teeth, they concluded that nano-composite denture teeth exhibited statistically significantly more wear than the two PMMA denture teeth. In regard to PMMA teeth, there is a highly crosslinked structure without any fillers, which gives the denture 
teeth a homogenous structure. On the other hand, nanocomposite denture teeth contain inorganic silanized $\mathrm{SiO} 2$ fillers, which are incorporated into the structure to increase the hardness of the teeth; however, these fillers can be detached from the surface of the denture teeth during function and can lead to excessive wear.

Result of this study disagreed with other study performed by Ghazal et al ${ }^{(23)}$, that evaluated the wear in three types of denture teeth: feldspathic ceramic, nano-filled composite resin (NCR), and experimental acrylic teeth (AR) teeth. They stated that NCR teeth seemed to be more suitable for complete dentures and partial dentures because of their good wear resistance. Ghazal and Kern performed another study where direct comparison of the wear resistance of the nanofilled composite teeth with human enamel was done which reflected the fact that enamel showed less wear among the two ${ }^{(14)}$.

The difference may be explained using different testing methods and different specimen preparation methods. The low wear resistance of nanocomposite teeth might be explained by comparing the composition and wear mechanisms of the denture teeth. The amount of wear of nanocomposite teeth was clinically relevant for the complete denture prosthesis. This amount occurs after 10,000 cycles of wear simulation, which corresponds to about 1 month of use of the complete denture. With this amount of wear, the complete denture occlusion has to be checked to avoid the sequela of excessive wear of the denture teeth causing loss of vertical dimension or temporomandibular joint dysfunction.

The amount of pressure used during the wear simulation in this study was 700 gram. This amount is higher than the amount of pressure calculated from the literature for complete denture occlusion $(0.4 \mathrm{~kg})$. This higher level of pressure was chosen to simulate the worst-case scenario, as in a case of high occlusal contact, bruxism, or improperly balanced complete denture occlusion that could lead to increased pressure in isolated areas and exhibit more wear

\section{CONCLUSION}

Within the limitations of this study, the following conclusions are drawn.

This study confirmed the fact that the nanocomposite denture teeth had comparable wear resistance with acrylic denture teeth, but the difference was non-significant. Further developments in materials science have to produce much more wear-resistant artificial teeth, which are equally suitable for human enamel and thus solve the question of prosthesis wear

\section{REFERENCES}

1. Winkler S. Essentials of complete denture Prosthodontics, 2nd edn. ATIBS, Delhi, 2012; p 222

2. Mahalick JA, Knap FJ, Weiter EJ. Occusal wear in prosthodontics. J Am Dent Assoc 1971;82:154-9.'

3. Ogle RE, Davis EL Clinical wear of three commercially available artificial tooth materials: thirty-six month results. J Prosthet Dent 1998; 79:145-151

4. Reis KR, Bonfante G, Pegoraro LF, Conti PC, Oliveira PC, Kaizer OB. In vitro wear resistance of three types of polymethyl methacrylate denture teeth. J Appl Oral Sci 2008;16(3):176-180

5. Ohlmann B. Influences on clinical wear of acrylic denture teeth: a Pilot study. Int J Prosthodont 2007;20:496-498

6. Chang JC, Katz ST. Composite denture teeth made on a removable partial metal framework. J Prosthet Dent 1994;71(4):409-412

7. Munshi N, Rosenblum M, Jiang S, \& Flinton R, In Vitro Wear Resistance of Nano-Hybrid Composite Denture Teeth. J Prosthodont. 2015 Nov 30. doi: 10.1111/ jopr.12412.

8. Elshereksi N, Ghazali M, Muchtar A, et al: Perspectives for titanium-derived fillers usage on denture base composite construction: a review article. Adv Mater Sci Eng 2014;2014:1-13 
9. Gracis SE, Nicholls JI, Chalupnik, et al: Shock-absorbing behavior of five materials for materials used on implants. Int J Prosthodont 1991;4:282-291

10. Kawano F, Ohguri T, Ichikawa T, et al: Shock absorbability and hardness of commercially available denture teeth. Int J Prosthodont 2001;15:243-247

11. Ilangkumaran R, Srinivasan J, Baburajan K, Balaji N. Two Body Wear of Newly Introduced Nanocomposite Teeth and Cross Linked Four Layered Acrylic Teeth: a Comparitive In Vitro Study. The Journal of the Indian Prosthodontic Society. 2014;14(Suppl 1):126-131

12. Hahnel S, Behr M, Handel G, Rosentritt M. Two- body wear of artificial acrylic and composite resin teeth in relation to antagonist material. J Prosthet Dent 2009;101:269-278

13. Shetty MS, Shenoy KK. An In Vitro Analysis of Wear Resistance of Commercially Available Acrylic Denture Teeth. Journal of Indian Prosthodontic Society. 2010;10(3):149-153.

14. Ghazal M, Kern M (2010) Wear of denture teeth and their human enamel antagonists. Quintessence Int 41(2):157163

15. Coffey JP, DeLong R, Goodkind RJ, Douglas WH. In vitro study of the wear characteristics of natural and artificial teeth. J Prosthet Dent 1985;54:273-280
16. Zhou ZR, Zheng J. Tribology of dental materials: a review. J Phys D Appl Phys 2008;41(11):1-22

17. Heintze SD, Faouzi M, Rousson V, Ozcan M () Correlation of wear in vivo and six laboratory wear methods. Dent Mater 2012;28(9):961-973

18. Lambrechts P, Debels E, Landuyt KV, Pneumans M, Meerbeek BV. How to simulate wear? Overview of existing methods. Dent Mater 2006;22:693-701

19. Latta M, Shaner J: Localized wear of denture tooth materials. IADR Barcelona 2010. \# 4068. Available online at https://iadr.confex.com/iadr/2010barce/webprogram/ Paper140085.html.

20. Lambrechts P, Braem M, Vanherle G. Buonocore memorial lecture. Evaluation of clinical performance for posterior composite resins and dentin adhesives. Oper Dent 1987;12:53-78.

21. Okeson JP. Management of Temporo-mandibular Disorders and Occlusion. St. Louis: Mosby; 1989. p. 259-60

22. Hirano S, May KB, Wagner CW, Hacker CH. In vitro wear of resin denture teeth. J Prosthet Dent 1998;79:152-155

23. Ghazal M, Hedderich J, Kern M. Wear of feldspathic ceramic, nano-filled composite resin and acrylic resin artificial teeth when opposed to different antagonists. Eur J Oral Sci 2008;116(6):585-592 